\title{
DORA GARCÍA: LENGUAJE, ESCRITURA, LIBROS EN EL ARTE
}

Túa BLESA

Universidad de Zaragoza

$\mathrm{Q}$

ue el arte de los últimos cien años, cien poco más o menos, viene mostrando un interés, y estoy por decir que en muchos casos una predilección, por el lenguaje ya sea en cuanto discurso oral o escrito, ya por los libros, por el texto en general, un texto que en ocasiones es literario, es algo manifiesto. Sin pretender trazar una genealogía, como meros ejemplos, han de tenerse en cuenta las leyendas que René Magritte pinta, y con qué cuidado las caligrafía, en tantos de sus trabajos, con lo que la lectura en su sentido más estricto pasa a formar parte de la percepción de la pieza junto a los objetos representados -la letra, las letras, la leyenda está, entonces, en el cuadro en cuanto (re)presentación (Blesa 2011)-, o, para mencionar ahora artistas españoles, ahí están las letras y palabras y aun agrafismos - ¿y qué decir entonces de su lectura?-que Antoni Tàpies inscribe en no pocos de sus trabajos, o las esculturas de figuras humanas hechas o cubiertas de letras de Jaume Plensa -en los trabajos de uno y otro la letra está allí en su ilegibilidad- o los libros tan maltratados, una forma en último término de hacerlos presentes, de Alicia Martín, muestras de una extensa nómina de esa atención de los artistas al lenguaje en sus diversas manifestaciones.

Y está además el hecho de que no son pocos los casos de artistas que en su formación no sólo cuenta el arte sino también la literatura y no habrá que olvidar que tampoco son escasos los artistas que producen, a la par que sus piezas artísticas, textos, ya ligados a ellas, ya sin vinculación directa con las mismas. Textos, entonces, que algunos de ellos, más que hacia el territorio del arte, se deslizan hacia lo literario o que son, digámoslo directamente, literatura. Michelangelo Buonarroti, que dejó en la escultura, en la pintura y en la arquitectura obras memorables, escribió un buen número de sonetos y algunos otros poemas, William Blake fue un notable pintor y grabador, y tiene un lugar en la historia de las artes, pero su obra poética, que es de excelencia, le ha hecho merecedor de otro y de gran relieve en la historia de la literatura universal, y en fin los escritos de Marcel Duchamp, aunque un algo oscurecidos por su faceta de artista, no pueden ser relegados a cosa menor, ahí están los que conforman la serie de Rrose Sélavy, ese muestrario de retruécanos que llegan a implicar incluso a más de una lengua. Ahora bien, a propósito de los ejemplos mencionados, y de otros muchos, sucede que, dado que la distinción entre lo literario y lo artístico está 


\section{Túa Blesa}

institucionalizada, ya fijada por una decisión previa a la consideración de la obra de que se trate, Buonarroti y Duchamp son artistas y casi sólo artistas, relegando a la oscuridad su literatura. En cuanto al mencionado Blake, los problemas surgen de que el mestizaje de algunos de sus trabajos, tales como Songs of Innocence and of Experience o The Marriage of Heaven and Hell, conocen ediciones, ya en inglés, ya traducciones, ya selecciones antológicas en las que se reproduce el texto poético y, por las múltiples razones que sean -técnicas, económicas u otras-, la parte artística de la página, está desaparecida, con lo que esas piezas híbridas, texto verbal + lámina, que son los originales pierden su mestizaje y los resultados sólo pueden ser calificados como tergiversaciones, amputaciones de lo que verdaderamente son. En los aludidos casos Blake-poeta desplaza a Blakeartista en nombre de la ley que institucionaliza que una cosa es la poesía y otra el arte y Blake es, antes que ninguna otra cosa, poeta y los poemas son, por una ley que transgrede la naturaleza de las cosas, discurso verbal.

Del trabajo de Dora García, cuya obra es ya a estas alturas abundante y de todo punto interesante, inquisitiva, hablan estas páginas. Obra plural que incluye vídeos, instalaciones, performances... con una sobresaliente y mantenida presencia del lenguaje en sus diversas formas de habla, libros y textos; una obra artística en la que la textualidad es componente decisivo. Obra plural que una y otra vez incide en una reconstrucción del cartografiado de los espacios aislados de las artes que apunta a borrar o, cuando menos, difuminar las fronteras que marcarían esos aislamientos y ello por cuanto en las piezas de esta artista lo lingüístico, literario o no, es un ingrediente fundamental.

Entre los textos de Dora García los hay a propósito del arte y, además de sumamente interesantes sobre la problemática cuestión del arte hoy, la del arte contemporáneo, la del arte después del fin del arte, para decirlo con la feliz expresión de Arthur C. Danto, y que iluminan su propio quehacer, tienen valor por sí mismos y son, en este sentido, literarios sin más. E importa subrayar que en ellos no suelen faltar las referencias literarias, referencias a obras y autores que muestran a Dora García como una lectora poco común. Así, por ejemplo, en «...he medido mi vida con cucharitas de café...» (García 2012) -y el título es ya todo un aviso-, un escrito a partir de trabajos de Ignasi Aballí o para acompañarlos, se mencionan o citan The figure in the carpet de Henry James, Der Räuber de Robert Walser y éstos son sólo algunos de una nómina de los que denomina artistas sin obra, de hombres sin propósito, que incluye tanto a autores como personajes literarios y del cine, nómina que incluye a Charlot, Buster Keaton, también Laurel y Hardy, Leopold Bloom, el Zeno Cosini de Italo Svevo, el príncipe Myshkin de El idiota de Dostoyevski, Daniil Charms -tan escasamente leído; la artista no dejó de incluirlo junto a otros doce en la relación de su Men I love-, el artista del hambre de Kafka, J. Alfred Prufrock, Bouvard y Pécuchet, el Silvestre Paradox de Baroja, Monsieur Teste, Bartleby el escribiente, o los personajes de En attendant Godot y Film de Beckett, que sería interpretada, entre otros, por Keaton, donde, a la vista está, lo literario predomina, además de que ha de subrayarse que las lecturas mencionadas extienden un certificado a favor de Dora García que la acredita como una excelente y exigente lectora. 
Esta categoría de artistas sin obra, tan ingeniosa como incisiva - ¿se puede ser artista sin obras?- está también en el origen de la performance de Dora García The Artist without Works (2002 y años posteriores), en la que en un espacio dedicado al arte, un museo, una galería, donde se ha anunciado una exposición, un o unos personajes -en realidad unos actores-conducen al público por ese espacio y van dando noticia sobre las obras de un artista que es un artista sin obra alguna y, por tanto, informan sobre la inexistencia de obra, una ausencia de obra de la que se habla, sin embargo, invocando a su autor, o quizá mejor su «autor», y sus obras, también quizá mejor «obras», invocado todo ello en un espacio reconocido como vinculado al arte y en un discurso del que habrá que decir que pertenece, pese a la obra inexistente, a la crítica o la teoría del arte y expuesto a un público que ha acudido a un acto marcado por el arte, interesado, pues, por el arte, que está a la espera de que pasen las presentaciones y llegue el momento de iniciar el recorrido y tener a la vista las obras de las que se habla, una espera que no tiene término, espera que queda en espera por cuanto son inexistentes los referentes del discurso. Así, el vacío es lo que está en el centro de la acción, el espacio y las palabras y su auditorio, elementos que estando todos ellos marcados por lo artístico están sostenidos sobre lo que ha de ser nombrado como nada. Ausencia de obra que, sin embargo, produce un comentario que la nombra, la caracteriza. En cuanto al personaje, no estará de más dejar noticia de su complejidad. En 2008 Art Basel Miami Beach se presentó Crowd. The Artist without Works. A Guided Tour Around Nothing con la colaboración de Jan Mech. En los mensajes previos a la performance intercambiados entre García y Mech, quien habría de ejercer como guía-actor -y que ha colaborado en varias otras performances de Dora García-, a la pregunta de éste sobre el personaje que ha de representar, la artista le comenta: «The character you play is a tour guide that has gone a bit whacky. I mean, he is a tour guide who knows he is an artwork, and at times he thinks he is an artist without works» (García 2009: 44), en lo que «The character you play» no podría pasarse por alto de ningún modo. $\mathrm{Y}$ en cuanto a la pieza en su conjunto, en esa misma correspondencia, a la observación de Mech de que The Artist without Works le parece un algo nihilista, escribe García «It is not nihilistic about art or about itself. It is nihilistic, sarcastic even, about art fairs, art fairs' audiences, performances and sculpture parks. It deals with an impossibility, a contradiction, and a frustration»(García 2009: 45-46). Nihilista o no, este trabajo plantea al menos dos cuestiones intrigantes. Una es el discurso crítico sin referencia, la palabra del guía de la visita que se pronuncia sobre el vacío, sobre la ausencia de obra, crítica sin objeto alguno sobre el que los comentarios se sostengan, imagen turbadora para los discursos sobre el arte, para estas mismas páginas, pongamos por caso. No estará de más dejar constancia de que The Artist without Works cuenta, entre otros precedentes, con Sartor Resartus de Thomas Carlyle, «Pierre Menard, autor del Quijote» o «Examen de la obra de Herbert Quain» en Ficciones de Jorge Luis Borges o los textos recogidos en The perfect Vacuum -el primero de los textos borgianos mencionados es citado en las páginas del capítulo «Rien de tout, ou la conséquence»- o Library of the 21th Century de Stanislaw Lem, páginas todas ellas que resumen, comentan, etc., páginas de libros inexistentes, parodias de la crítica. Y ya Rabelais había mencionado algunas lecturas fantasmales en su narración monstruosa. Por los azares de la 
historia, por la erosión de la cultura que ejercen los mil y un avatares acontecidos, un precedente, para el lector moderno, en este tipo de escritura -el que incluye nombres de obras sin obras-, sería Aristóteles y los pasajes de su Poética en los que se mencionan obras que no han llegado hasta nosotros, si bien existieron y para Aristóteles y sus lectores de la época esas menciones no fueron en modo alguno precedentes de esta modalidad textual sobre textos inexistentes. En fin, vacío perfecto resulta ser expresión adecuada para The Artist without Works.

La segunda de las cuestiones viene a ser contrapartida o consecuencia de la anterior: los asistentes, que han acudido para conocer unas obras y a quienes se habla de ellas, escuchan los comentarios e inevitablemente componen su propia imagen de las obras inexistentes, por lo que la inexistencia de ellas es ya relativa. Por mucho que esas piezas de las que se habla no estén a la vista de los asistentes, ni ocultas, a la espera, en ningún otro lugar, las palabras que hablan de ellas inducen a una cierta idea mental de las mismas, imaginaria sí, pero de la que en modo alguno se podrá mantener una inexistencia total y absoluta, pese a ser obras inmateriales, sin presencia, pues ya no se puede decir que estén carentes de una cierta forma de realidad, realidad imaginada, una «realidad» que además será múltiple y variopinta, con una representación por cada una de las personas reunidas ante el guía -qué tipo de obras sean, sus temas, sus estilos, sus texturas, de qué están hechas, etc.- por mucho que todas esas «realidades» no tengan asidero material alguno en el mundo, obras que son, puesto que sin referencia, fantasías. Así, las obras del artista sin obras, inexistente el artista, inexistentes las obras, cobran, aunque sea en forma espectral, imaginada, su particular y múltiple forma de existencia. Una forma de existencia que, por otro lado, será semejante en todo a la de, pongamos por caso, el «plump Buck Mulligan» que sube las escaleras de Martello Tower al comienzo del Ulysses -y que para algunos esté identificado el modelo real en que se basó Joyce para el personaje no añade ni quita nada a lo dicho-, o a la de Leopold Bloom, al riñón que se prepara para el desayuno y comparte con la gata y con ello todos los mundos de la literatura y todo aquello que los puebla, ese tipo de existencia que dan a las gentes, a las cosas, a los acontecimientos narrados la escritura y la lectura. Existencia ficcional. De ese mismo tipo se puede decir que es el de las obras del artista sin obras. Así, este trabajo de Dora García, institucionalmente una artista, lo que pone en obra es la ficción, ese singular modo de realidad que, antes que pertenecer en este caso al arte, es propio de la literatura. Y sucede que The Artist without Works, y claro que no es el primer ni el único caso, reterritorializa los ámbitos tradicionales asignados al arte y a la literatura. En ese mismo sentido, esta performance, como es lo propio de esta clase de acciones, ¿en qué se diferencia del teatro? Alguien, actor profesional o no, interpreta un papel, el de guía en un museo, en una galería, habla ante un público y ¿no es eso una representación? The Artist without Works ¿no lleva lo teatral, marca de las performances, a la institución «teatro»?

El lenguaje, las lenguas, la palabra, ocupa de nuevo el centro de la performance $E l$ mensajero/The Messenger, llevada a cabo en varias ciudades del mundo en diferentes años. Cuando menos, Bruselas en 2002, París y Barcelona en 2006, Metz, Hong Kong y Copenhague en 2008, Niza, Toulouse y Guadalajara (México) en 2010 son espacios que Dora García y sus cooperadores en 
las diferentes ocasiones convierten durante unos días en una nueva Babel a la búsqueda de alguien que comparta la lengua de un mensaje, no importa quién sea, el receptor se deja al azar. En efecto, la performance consiste en que el ayudante de la artista recibe un mensaje en una lengua que desconoce, lo memoriza y comienza su peregrinar entre las gentes de la ciudad elegida, en su errancia a la sombra siempre de la torre babélica va entablando conversación con quienes estima oportuno, les explica que tiene un mensaje que ha de transmitirlo a alguien que lo entienda, lo pronuncia, no le entienden, le dan alguna pista sobre la lengua de aquella frase incomprensible para uno y otro o de dónde podría encontrar a quien cerrase el acto comunicativo y el peregrinaje continúa. Se suceden nuevos interlocutores, nuevas hipótesis sobre la lengua de aquello que es puro significante, casi ruido, sobre el lugar en que quizá alguien podría comprenderlo, y el cometido del mensajero no acaba hasta que la frase críptica es pronunciada ante una persona que finalmente la comprende. El objetivo se ha cumplido, el mensajero ha entregado el mensaje. El participante, además, va redactando un diario de las conversaciones que promueve, de las personas con quienes éstas se llevan a cabo, de los lugares en que se producen, en fin, de las múltiples circunstancias de su tarea verbal, relato que se acompaña de fotografías en algunos de los casos de las personas a las que se aborda, etc., todo lo cual constituye la documentación de la performance. La documentación, no la performance.

Dejando aparte lo que de experimento sociológico o psicológico pueda verse en El mensajero, la performance consiste en una cadena de escenas o situaciones teatrales, en las que se reúne lo previsto, digamos el guión, y lo imprevisto, la improvisación. El actor sabe cuál es su papel -sabe, sobre todo, su frase, la frase que no sabe lo que dice- y lo ha de ir moldeando sobre las reacciones con las que se encuentra en una interpretación cuyo final, el momento del final, está absolutamente indeterminado. Así, teatro, literatura, escenas de lenguaje. Y El mensajero a lo que da lugar es a un relato, a unos relatos, cuyas características dependerán del estilo de habla, del estilo narrativo del performer, y en un caso estará lleno de detalles, en otro será más escueto. Ese relato, que no es la performance, sino su documentación o parte de ella -en alguna de sus realizaciones se incluyen imágenes, como ha quedado dicho-, se da en una acción que se entiende como artística, pero en sî mismo es narración, es literatura. Se trata, por una parte, de un relato de intriga, un realto que pertenece, por otro, a lo autobiográfico, a un autobiografismo en el que el pacto típico de esos géneros está aquí despejado de dudas, inquebrantable; un relato, en el que el personaje narrador, aunque quizá mejor que denominarlo personaje será llamarlo persona, se nos presenta desde el primer momento en su tarea de búsqueda, cuenta cómo, pronunciando su frase incomprensible para él, va tras la persona, por el personaje, que ponga fin a su misión, a lo que puede nombrarse como la tarea del héroe para emplear un término tan reiterado en los estudios literarios. En esa persecución, la persona, el héroe, encontrará ayudantes, se topará con dificultades, como sucede en tantas narraciones y, desde luego, reproduciendo una estructura narrativa que se ajusta al modelo de Vladimir Propp y, de hecho, los relatos a los que da lugar El mensajero parecen estar invitando a ser 
analizados desde la narratología ${ }^{1}$. Y es que en este y otros trabajos de García hay una narratividad que es rasgo común con abundantes otras piezas del arte contemporáneo, como ha señalado David G. Torres en su No más mentiras (G. Torres 2011), lectura, por cierto, de lo más interesante; una atención a la narración que se hace expresa en Instant narrative, el título de otro de los trabajos de la artista. De esa búsqueda del mensajero, por otra parte, se hace partícipe el lector del diario del performer de un modo en todo semejante al proceso que sigue el lector de la novela policíaca, si bien la pregunta ¿quién es el asesino? está sustituida ahora por otras del tipo ¿encontrará a quien comprenda?, ¿qué es lo que dice la frase del mensajero?

Lo que es central y como la pregunta en cuestión evidencia El mensajero es posible por una frase, unas palabras, por un hecho del lenguaje. Una frase que es incomprensible para quien la pronuncia, para muchos de los que la oyen. La palabra, la comunicación, la imposibilidad de la comunicación verbal entre quienes no comparten una lengua, vueltas y vueltas en torno a la torre de Babel -una Babel que es ahora Bruselas, Hong Kong, etc.- mientras se escuchan palabras, palabras para nadie, no para el emisor, que, inocente, no sabe lo que dice, no para éste y el otro y el otro de los receptores, palabras que son sólo sonidos sin significación, ruido para los participantes, faltos como están del código en el que la frase se cifró, a excepción del que será el último oyente, el que posee el código que desentraña la secuencia verbal.

Y la frase es incomprensible, un cierto modo de ser ilegible, aun para el lector del diario e incluso, en el caso de este último, al final del texto. En la ocasión de Bruselas, por ejemplo, «Labas. Ar jus mane suprantat?» es la enigmática frase de, en este caso, la mensajera, Sybille. Cuando, tras preguntar a unos y otros, seguir sus sugerencias, cuando en su peregrinar encuentra quien entienda el mensaje, cuando ese silencio en forma de ruido se transforme en texto comprensible, se deja esta última anotación:

We go through the ceremony of Turkish coffee, we discuss about banalities and smile a lot and are really happy to be there. Then the woman asks:

«How did you find us?»

And Sybille tells the story.

«Why do you want to deliver the message?»

«...because... we found the message on the net. We didn't know which language it was but we believed it was something terribly important. So we were determined to discover the meaning of it: first we found out it was Lithuanian, then we tried to find some Lithuanian people...»

«What is the message?»

And Sybille recites the message again.

And the woman tells us what the message means (García 2002).

El mensaje ha sido comprendido, la mensajera y su ayudante oyen al fin su significado -se supone-, el lector del diario lee que el objetivo ha sido alcanzado, pero a ese desvelamiento no se le

\footnotetext{
${ }^{1}$ Y ya que se menciona la narración y que su estudio es uno de los campos en los que Enric Sullà ha dejado trabajos significativos, aprovecho la ocasión para dejar aquí constancia de la deuda que los estudios de teoría de la literatura en España tienen con su investigación, su docencia y su dedicación a la Asociación Española de Teoría de la Literatura. Y, cómo no decirlo, la deuda, mía y de tantos, de la amistad. Estas páginas homenajean a Enric Sullá, l'amic Enric.
} 
da acceso, el lector no sabrá lo que «Labas. Ar jus mane suprantat?» pueda significar, con lo que quedan sin cumplirse las expectativas de la lectura ${ }^{2}$.

Pese a todo lo anterior y como es evidente, El mensajero es una pieza de Dora García, de una artista - de ello no cabe duda-, que pone en juego no un objeto artístico, es decir, no un cuadro, no una escultura, una instalación, etc., sino situaciones en la vida real, encuentros con otras personas, diálogos que se reproducen, de lo que las notas del diario del performer dan cuenta, como si levantasen acta notarial, aunque un acta que no se atiene a los protocolos notariales. El lenguaje, puesto en juego.

Está, por otro lado, la presencia de textos, textos en su formato de libros, en algunos de sus trabajos considerados sin más propios del espacio del arte, libros, por cierto, nada vulgares como se verá. Es el caso de la película The Joycean Society (2013), donde todo se desarrolla a partir de la novela de James Joyce Finnegans Wake, de nuevo un vínculo con Joyce. Como ha explicado García, los miembros de la sociedad de la Zürich James Joyce Foundation

reescriben el libro al leerlo, y esto es literalmente. Cada lectura del libro les lleva once años [...] y cuando al cabo de once años vuelven a pasar por la misma página, son incapaces de entender sus propias anotaciones de años atrás, y otras nuevas se escriben sobre las anteriores [...] Ese modo de lectura-escritura se parece mucho a la que Joyce utilizó para escribir el libro. Todo empezaba de un modo simple, una frase que después se ampliaba y se retroalimentaba. Me dicen que cuando escribía solía salir a la calle y apoyarse en cualquier esquina a tomar notas (García 2013).

Así, en lo que este trabajo artístico consiste -y de que pertenece al arte no cabe ninguna duda hay que recordar una vez más- es en abordar asuntos literarios y no precisamente marginales en ese campo sino centrales, como son la escritura, la lectura y, con palabras de la artista, la lecturaescritura. Al respecto, importan estas palabras de Dora García «hay un paralelismo entre cómo se escribe el libro y cómo se lee, y esa idea latente de fracaso» (García 2013), lo que conecta esta obra con las propuestas derridianas sobre imposibilidad de la lectura de todo texto, así, ya en $L a$ dissémination (1973), las primeras palabras de «La pharmacie de Platon» -publicado antes, en 1968hacían saber que «Un texto no es un texto más que si esconde a la primera mirada, al primer llegado la ley de su composición y la regla de su juego. Un texto permanece además siempre imperceptible» (Derrida 1975: 93), lo que si atañe a todo texto, de qué modo hace evidente esa ocultación Finnegans Wake, escrito no en una lengua, sino en una lengua de lenguas, una archilengua. Y cuánto más cuando sucede en esa novela que la linealidad de la escritura, del texto, es curva hasta la circularidad por la exigencia del «the» final que remite al «riverrun» inicial e introduce de nuevo en el laberinto sin salida de la lectura reiterada, aunque cada vez nueva, o bien, pues no es unánime esta

\footnotetext{
${ }^{2}$ Como curiosidad, dejo aquí esta nota. Sabiendo que la frase está en lituano, busco en los traductores de internet, que me ofrecen los siguientes resultados: «Hola. ¿Te suprantat conmigo?» (http://servicios.elpais.com/traductor/index.

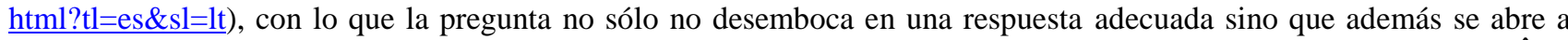
otras; pruebo allí mismo la traducción al francés y obtengo, con supresión de la marca de interrogación (?), «Salut. Êtes vous suprantat moi», pruebo al inglés y «Hi. Are you suprantat me», nada de lo cual ayuda a cerrar ni la pregunta capital ni las derivadas. Además de algunos otros resultados semejantes, se me ofrecen estos otros que copio literalmente: «Hola. ¿Todos me entiendes?», «Bonjour. Avez-vous tout compris?», «Hello. Do you all understand me?» (http://www.lexicool.com/diccionario-traduccion-lituano.asp).
} 
interpretación, el «the» final no reenvía a «riverrun» y es el cierre, un cierre que, dada la naturaleza gramatical de esa pieza, se proyecta sobre una o más palabras que ya no constan en el texto, que, pues inacabado, logofágico (Blesa 1998). Cuando García habla de fracaso, ese fracaso es el de Joyce, el del lector, el del artista, el de quien se sitúa ante la obra de arte, ya por su circularidad, ya por su inacabamiento.

Por lo demás, es obvio decir que en las imágenes de García la work in progress joyceana, esa titánica labor de escritura que dio en una de las novelas más aborrecidas por algunos, al tiempo que más veneradas por otros, es la estrella. Pero también Ulysses se presenta en numerosas ocasiones. Ulysses, por cierto, guillotinado en una de sus esquinas y cerrado, Finnegans Wake, por su parte, abierto, ofrecido a la lectura, con sus páginas profusamente anotadas, destacadas algunas de sus palabras, marcas de la lectura (imposible), de la interpretación (imposible), riverrun, la lectura que fluye, la interpretación que fluye, riverrun.

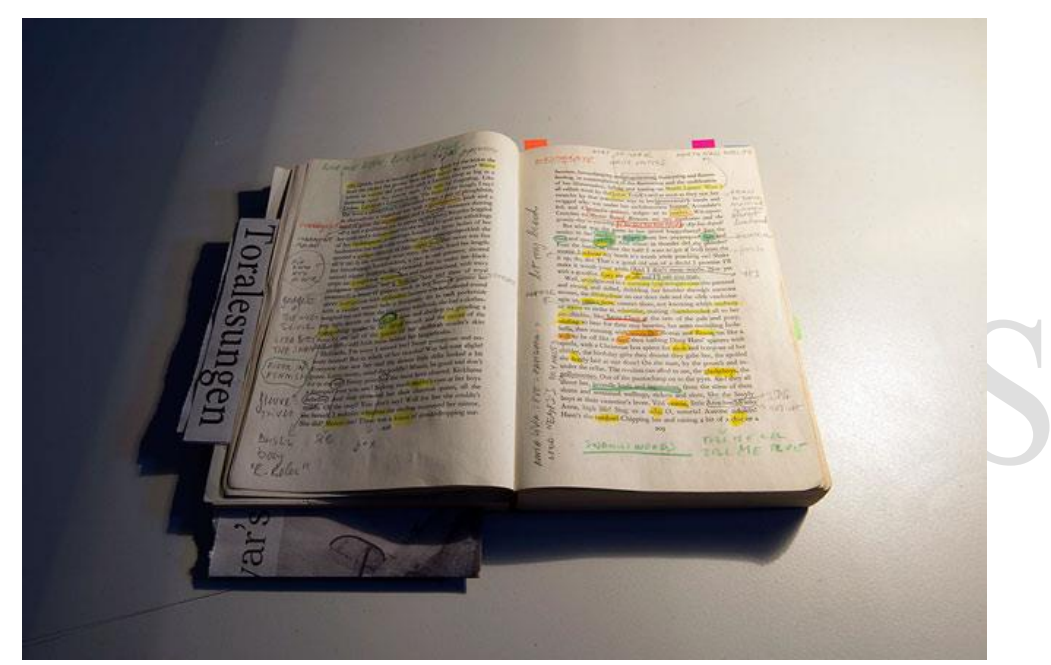

Fig. 1 The Joycean Society

«iPor Dios, hermana mía! Cuéntanos una historia para distraernos del insomnio de esta noche» (I, 15) y, como es bien sabido, ante ese ruego toma la palabra Sahrazad y ahí comienza una narración que, uniendo relatos a relatos, prolongándose noche tras noche durante mil y una noches, es la imagen de la narración infinita, en cualquier caso, la narración que aplaza la muerte. La mención de esa extensa relación es más que adecuada para introducir una de las piezas más singulares de Dora García, la titulada «Todas las historias», cuyo titulo ya muestra la extraordinaria ambición del empeño: todas las historias y, como se dice en el texto de presentación, todas las historias del mundo. He aquí ese texto:

Aquí se enumeran todas las historias del mundo. El lector que decida leerlas en voz alta se convierte en performer de Todas las historias y, cuando haya terminado, todos los hombres y mujeres, todo el tiempo y todos los lugares, habrán pasado por sus labios. La dificultad estriba en que cada día nuevas historias se añaden a esa lista (García 2001b). 
Por si no quedara suficientemente clara la idea, la primera de las historias reitera la infinitud del proyecto: «Un hombre recita en voz alta todas las historias del mundo. Cuando haya terminado, todas las historias, todos los hombres y todas las mujeres, todo el tiempo y todos los lugares habrán pasado por sus labios» (García 2001b).

La pieza, bien se comprende, no puede ser más que un proyecto, como ya ha quedado dicho, un deseo, un abrir un espacio, un tiempo, para la palabra en una apertura sin clausura posible - «cada día nuevas historias se añaden a esta lista»-, a no ser la que traería la catástrofe definitiva, la catástrofe con la que llegaría, entre otras cosas, el verdadero y definitivo fin del arte, de la palabra. De todos modos, en lo que consiste la performance, que es, y no puede dejar de serlo, proyecto, no es tanto las historias escritas y por escribir, todas las historias, cuanto el que alguien decida recitarlas, el que alguien se instituya en performer. Esto suscita algunas preguntas: ¿aquel que tome la decisión del recitado ha de hacerlo ante un cierto auditorio aun mínimo?, ¿basta con que sea la misma persona el emisor y el receptor de todas las historias en voz alta, que se las recita? En cualquier caso, quien da ese paso y se sitúa en el lugar del performer, quien toma la decisión de reencarnar a Sahrazad, sabe de antemano que su performance está abocada al fracaso -recuérdese que García habla de fracaso a propósito de Finnegans Wake-, nunca leerá todas las historias del mundo, sí quizá cientos de ellas, quizá las casi tres mil que en estos momentos están escritas, las que pueda llegar a haber en un futuro, pero, está claro, jamás todas.

Todas las historias es, pues, la lectura en voz alta de las historias escritas y las que están aún por escribir, pero ese proyecto tiene algunas otras manifestaciones. Además de las historias contenidas en el archivo virtual (http://www.doragarcia.org/todaslashistorias/ y http://alepharts.org/insertos/todaslashistorias/todaslashistorias.html), la condición necesaria para que pueda darse la performance, su sustento, lo que invita al lector a constituirse en performer, se han publicado varios libros que recogen las historias y vídeos donde se documenta la performance, la lectura en voz alta de historias, de algunas de las historias de Todas las historias.

Las historias de Todas las historias son relatos mínimos. Así, la que inauguró la serie indefinida antes citada, la segunda de ellas: «Un hombre sueña toda su vida el mismo sueño. Incluso cree que en realidad está viviendo dos vidas, la una interrumpiendo la otra según duerme o se despierta»; o la que a día de hoy, la redacción de estas páginas, cierra la serie en un cierre que es ya apertura, la 2989: «Los libros de ficción abarcan un solo argumento, con todas las permutaciones imaginables. Los de naturaleza filosófica invariablemente contienen la tesis y la antítesis. Un libro que no encierra su contralibro es considerado incompleto». Aires borgianos. Así, en «La Biblioteca de Babel» se informa lo siguiente: «en el universo (que otros llaman la Biblioteca)» un pensador descubrió la ley fundamental, «observó que todos los libros, por diversos que sean, constan de elementos iguales», que, si bien resultan ser «el espacio, el punto, la coma, las veintidós letras del alfabeto», esa ley permite la posibilidad de otra como la antes enunciada; y en cuanto a la cuestión libro-contralibro, también en esos mismos anaqueles, se encuentran «el catálogo fiel de la Biblioteca, miles y miles de catálogos falsos, la demostración de la Falacia de esos catálogos, la demostración de 
la falacia del catálogo verdadero» (Borges 1972: 67 y 70). Además, la hoy última historia vuelve en un bucle sobre el conjunto, Todas las historias no puede ser de ninguna de las maneras todas las historias y el título está ya reclamando su contratítulo, un subtítulo que lo matice.

Otro de los comentarios que sugiere Todas las historias tiene que ver con la cuestión ¿es esto arte?, ¿no es literatura? Las historias de Todas las historias admiten plenamente una lectura literaria y no es que la admitan sino que son, así, sin más, literatura, en esa forma tan divulgada hoy del relato brevísimo.

En conexión con Todas las historias, así como con Las mil y una noches y de nuevo con Joyce, es la instalación Continuanarración. Tal título está tomado de Finnegans Wake: «Where did I stop? Never stop! Continuarration!» (205.13-14). Continuarración, la narración continua, la narración que se continúa en otra narración, narración tras narración, narrar y narrar, narrar continuamente, habría de llegar a comprender todas las historias. Continuanarración, un título que vuelve a hacer presente a Sahrazad, la que toma la palabra y ya no la deja y narra historia tras historia, la imagen de todas las historias, la continuarración, riverrun.

Todas las historias y Continuarración comparten la idea, la ambición, de totalidad, la totalidad del narrar, del habla. Esta misma idea reaparece en otro de los trabajos de Dora García, El cuaderno de notas (2001). Así se lee en el texto de presentación:

Una persona escribe en un libro. Escribe absolutamente todo lo que ocurre mientras escribe, desde el delicado sonido de los relojes hasta su propia, confusa, secuencia de pensamientos. Evidentemente, este registro compulsivo de todas las cosas afecta a sus propias acciones y reacciones, afecta a sus necesidades físicas y a su relación con los otros. Decide entonces dejar de escribir (García 2001a).

La idea de totalidad, siempre un algo sobrecogedora, está ahí, escribir todo, «absolutamente todo», en una tarea que vendría a ser, o a intentar serlo, un universo textual que doblase la realidad, todo lo que sucede a todos, un análogon de la realidad, del mundo, el mundo narrado. Un proyecto así, que no puede sino recordar al Livre de Mallarmé, del que el poeta supo que sólo podría llegar a elaborar un fragmento, tal como explica en la «Autobiographie» que le envía a Paul Verlaine: «non pas à faire cet ouvrage dans son ensemble [...] mais à montrer un fragment d'exécuté» (Mallarmé 1992: 663). Tal como ya supo Mallarmé, la persona que escribe, que pretende escribir, en un libro «absolutamente todo lo que ocurre», para decirlo con las palabras de García, lleva unido en su propósito la imposibilidad de su tarea y acaba por comprender que ha de desistir, que ha de dejar de escribir, de nuevo la idea del fracaso. Pero, como también dejó escrito Mallarmé, con lo que se pueda llegar a hacer de esa empresa sobrehumana habrá de bastar para mostrar la posibilidad de culminarla, dejar constancia, con algunos de sus fragmentos, de la existencia de esa totalidad, de que se la conoce, ha sido pensada. «Prouver par les portions faites que ce livre existe, et que j’ai connu ce que j'aurai pu accomplir» (Mallarmé 1992: 663), es lo que añade a lo anterior. Por otra parte, la idea de totalidad no es ajena, sino todo lo contrario, a Joyce. Y, en fin, sobre la imposibilidad ha escrito Dora García que Vladimir y Estragon, Monsieur Teste, Silvestre Paradox y el resto de los artistas antihéroes, de los hombres sin propósitos 
Dora García: lenguaje, escritura, libros en el arte

\begin{abstract}
representan un movimiento fundamentalmente bello en la sensibilidad contemporánea, un modelo de comportamiento y un arquetipo: el paradójico Mensch que intenta «robar los días» para asegurar el sentido de ese tiempo que pasa, y es a la vez consciente de que tal tarea debe hacerse del modo más discreto posible, a fin de retrasar el momento en que su futilidad quede vergonzosamente patente para todos.

Nada hay más profundamente humano (Mensch!) que la realización de una tarea imposible (García 2012: 37).
\end{abstract}

A esta misma idea de análogon de la realidad responde Instant narrative, sólo que ahora la distancia entre lo que sucede y el relato de lo que sucede se reduce hasta alcanzar la casi simultaneidad, pretendiendo en último extremo que los sucesos y las palabras que los llevan a texto, que los hacen texto, mantengan entre sí una estructura de espejo, donde lo expuesto y su reflejo son, casi, coexistentes. En Instant narrative Dora García dispone un espacio con una pantalla en la que se proyecta un texto, un espacio en el que los visitantes entran, curiosean y a cada momento, escuchan cuáles es su aspecto, sus gestos, sus movimientos, etc. Todo se hace palabra, todo suceso, aun mínimo, encuentra al instante su narración, su análogon verbal. En esta pieza el visitante, aun sin saberlo, es quien, si no escribe, pre-escribe el texto que habla de él, un texto del que se puede decir que se escribe al dictado del que será su lector, lector futuro que dicta su lectura, la de sí mismo, con su sola presencia, con cada uno de sus movimientos, un texto que enseguida él mismo lee y en ese texto se sabrá leído. El visitante, la persona visitante, al leer las leyendas de la pantalla, se acaba viendo como personaje de una narración, viendo cómo su aspecto, la ropa que lleva, sus gestos, etc. se transmutan en palabras. En «Antes del almuerzo» de Ana María Moix, el personaje, que está leyendo un libro y ve cómo se rompe la línea que delimita el mundo en el que es lector, digamos el real, y el mundo del texto -lo perteneciente a éste se hace presente en aquél-, dice «me sentí irreal, leído», palabras que se diría escritas para el visitante de Instant narrative cuando lee lo escrito en la pantalla y se reconoce como referente de las palabras, cuando se lee. El visitante ha acudido allí a ver y resulta que ver es ser visto, curiosear es ser curioseado, observar es ser observado, comentar es ser comentado, lo propio regresa como ajeno, ajeno en cuanto discurso de otro, visto y enunciado desde otro. Está además todo lo que de Big Brother orwelliano, de ser observado, pone en acto Instant narrative.

Otro de los libros que han pasado a formar parte de un trabajo de Dora García es el que tiene el provocador título de Steal this book. Steal this book repite el título de un libro de 1971 de Abbie Hoffman que ocupa en la bibliografía universal un lugar extraño al animar desde su título a que sea robado y con ello a alterar el funcionamiento de los libros en nuestro mundo, una más de las acciones de Hoffman, un yippie, la facción activista del movimiento hippie, pasado por las enseñanzas de Herbert Marcuse; ese libro es una más de las acciones contra el sistema capitalista y muchas otras formaban parte del contenido del libro. Como dato curioso cabe consignar el hecho de que Amazon ofrezca la compra del libro al precio de 6’04 $€$ más gastos de envío ${ }^{3}$, si bien se puede acceder libremente a su lectura en diversos sitios de internet ${ }^{4}$. Steal this book de Hoffman se presenta como

\footnotetext{
${ }^{3}$ Los interesados pueden encargarlo en http://www.amazon.es/Steal-This-Book-Abbie-Hoffman/dp/156858217X (fecha de consulta: 2 de julio de 2014).

${ }^{4}$ Entre otros, en http://www.semantikon.com/StealThisBookbyAbbieHoffman.pdf.
} 
«a manual of survival in the prison that is Amerika»y, en efecto, enseña, o pretende enseñar, a vivir al margen del dinero, del capitalismo, en diferentes órdenes de la vida cotidiana, alimentación, transportes, sanidad, drogas, etc. Así, el hacerse con el libro sin pagar, robarlo, a lo que desde la portada se invitaba, no era más que el primer paso para acceder a una vida en los márgenes del capitalismo en una sociedad capitalista. Si Finnegans Wake llevó la novela a un punto que todavía no ha sido sobrepasado, el libro de Hoffman fue un libro que lanzaba un órdago al comercio libresco y, como se ha indicado, al sistema en su conjunto.

Dora García tomaba el título de Hoffman para una instalación en la que sobre una mesa se apilaban ejemplares de Steal this book, libro homónimo del de Hoffman aunque con un texto diferente. De todos modos, el paralelismo no acaba en el título del libro, sino que se prolonga en estos otros titulillos que conforman el grueso de la estructura: «Introduction» -en el libro de García «Introducción»e «Introduction»-, «Aiding and abetting», «Table of discontents» y, dentro de esta parte, «Survive!», «Fight!» y «Liberate!».

En el segundo Steal this book, el de nuestra artista, el contenido es otro. Tal como escribe François Piron en la «Introducción», de lo que en él se trata es de «documentar once proyectos realizados entre 2006 y 2008 por Dora García», documentación que se presenta en forma de epistolario, fundamentalmente correos electrónicos, mensajes cruzados entre la artista y algunos de los «intermediarios» de tales proyectos, tal como advierte Piron, «actores profesionales, aficionados o personas encontradas al azar» (García 2009: IV). Ahora bien, siendo muy distinto el texto de su predecesor, Steal this book ha cumplido una función muy semejante a la de aquél al formar parte de exposiciones de la autora. Impreso por miles, los ejemplares se exponían al público, se dejaban al alcance de la mano reclamando desde la portada el apoderarse de ellos, lo que implicaba una duda. ¿Es una escultura y, en cuanto objeto artístico, se me ofrece como intangible o acaso debería, o podría, tomar el reclamo al pie de la letra y coger libremente el libro? se pregunta el visitante, ¿acepto la llamada de la portada y cojo, robo, un libro, o estoy atentando contra la pieza?, ¿qué se espera de mí ante esa provocación? Los cientos de ejemplares están ahí, a la mano, ofreciéndose al visitante sobre un expositor reproducen el modo en que las secciones de libros de los grandes almacenes y aun de algunas librerías exponen los best-sellers, es una reproducción de lo real que prolonga las cajas de jabón Brillo de Andy Warhol y otras piezas posteriores, y antes el urinario de Duchamp, esa pieza tan perturbadora y decisiva para el arte, donde la cosa real, de consumo, se transmuta en pieza artística. Así, ahora los ejemplares de Steal this book (fig. 2). 
Dora García: lenguaje, escritura, libros en el arte

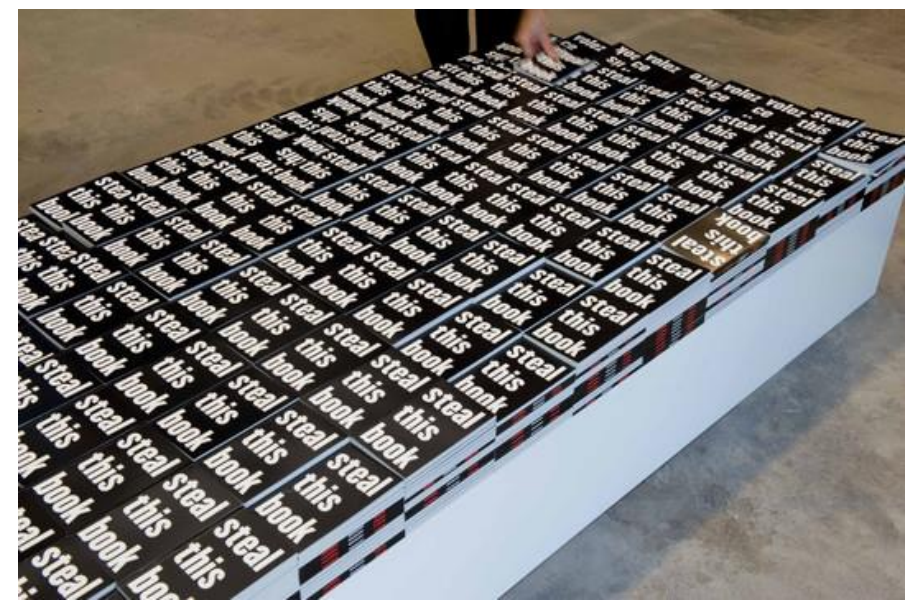

Fig. 2 Steal this book

Otro libro que ha provocado un trabajo de Dora García es la novela de Ray Bradbury Farenheit 451 , la bien conocida fábula de un mundo en el que los libros han de ser destruidos, tal como se destruyeron, entre otras ocasiones, en los años de la Alemania nazi y antes, en la literatura, la casi totalidad de los libros de Alonso Quijano van cayendo al corral destinados a alcanzar el grado de temperatura que da nombre a la novela de Bradbury. La instalación en cuestión, ¿Dónde van los personajes cuando la novela se acaba? -y, a la vista está, el título de este trabajo de Dora García remite una vez más a la literatura-, recoge 2.000 ejemplares de la novela con la particularidad de estar la impresión invertida, al estilo en que se presenta a la vista de la protagonista el poema «Jabberwocky» en Through the Looking-glass and what Alice found there de Lewis Carroll y que le hace decir a la niña «Why, it's a Looking-glass book, of course! And, if I hold it up to a glass, the words will all go to the right way again», lo que permitirá a Alicia, y a los lectores si hacen lo que ahí se dice, acceder del modo usual a la lectura del poema. En cualquier caso, tanto en una obra como en otra ha entrado en juego la ilegibilidad, bien que en forma de legibilidad incómoda, una ilegibilidad, atenuada, que, deslizada a Farenheit 451, la quema de todos los libros, es la ilegibilidad derivada de todo tipo de censura, de la persecución de la escritura, de la lectura, la negación de esos gestos, a fin de cuentas, tan humanos. Una ilegibilidad, relativa, que apunta a la absoluta de los libros quemados, los destrozados por el procedimiento que sea, los libros prohibidos, todos ellos lecturas desvanecidas en la era de la barbarie que transcurre al unísono que la de la cultura, como bien supo Walter Benjamin, también, por tanto, sus escritos trasladados penosamente en una maleta durante su huida de los nazis y perdidos. Portbou: cultura y barbarie.

Los volúmenes de Farenheit 451, como los de Steal this book, se apilan en la instalación. Unos y otros son producto de otros libros, sus títulos repiten los títulos de otros libros, derivan de otros, como no podría ser de otro modo, dado que todo texto sucede siempre a otro u otros. Libros que invocan a otros libros, los prolongan y los tergiversan y además los insertan en la serie libresca, al par que en la serie arte, una muestra más de cómo las realizaciones artísticas de Dora García se superponen sobre la linde entre la literatura y el arte, una linde que no termina de encontrar su justificación, y la desdibujan. 
16 Tropelías. Revista de Teoría de la Literatura y Literatura Comparada, 22 (2014)

Túa Blesa

Entre la totalidad y el vacío, o entre el vacío y la totalidad, las obras de Dora García sitúan el lenguaje, el lenguaje en cuanto habla, diálogo, narración, escenas teatrales, texto escrito, libro. Entre la totalidad y el vacío, y a la inversa, el lenguaje y la obra de Dora García, an artist with works.

\section{Referencias bibliográficas}

BLESA, T. (1998): Logofagias. Los trazos del silencio. Zaragoza, Trópica/Anexos de Tropelías. (2011): Lecturas de la ilegibilidad en el arte. Salamanca, Delirio.

Borges, J. L. (1972): Ficciones. Barcelona, Círculo de lectores.

DERRIDA, J. (1975): La diseminación. Trad. J. Martín Arancibia. Madrid, Fundamentos.

G. TORRES, D. (2011): No más mentiras. Sobre algunos relatos de verdad en arte (y en literatura, cine y teatro). Madrid, Trama editorial - Fundación Arte y Derecho.

GARCÍA, D. (2001a): El cuaderno de notas, en http://doragarcia.org/inserts/cuaderno/index.html (2001b): Todas las historias, en http://aleph-arts.org/insertos/todaslashistorias/todaslas historias.html

(2002): The Messenger, en http://doragarcia.org/inserts/themessenger/brussels/diary/index. $\underline{\mathrm{html}}$

- (2006): Mujer. Todas las historias. Castellón, Espai d'art contemporani de Castelló, (2009): Steal this book. Intr. F. Piron. París, Paraguay Press.

- (2012): «... he medido mi vida con cucharitas de café...», en Ignasi Aballí et al., This is not the end, Vitoria, ARTIUM, pp. 31-38.

- (2013): «Es un placer afrontar la difcultad», entrevista por Bea Espejo, El cultural (11 de octubre), en http://www.elcultural.es/version_papel/ARTE/33400/Dora_Garcia.

MAllarmé, S. (1992): «Autobiographie», en Oeuvres completes. Ed. H. Mondor y G. Jean-Aubry. París, Gallimard.

MoIX, A. M. (1974): Ese chico pelirrojo a quien veo cada día. Barcelona, Lumen. 